\title{
Post Trauma Morphea - A Brief Case Report
}

\author{
Dr Ebtisam Elghblawi \\ MBBCh, MScRes, ADD, DRH. \\ STJHTL, Tripoli-Libya \\ ebtisamya@yahoo.com
}

\begin{abstract}
Scleroderma is a chronic autoimmune disease characterized by progressive connective tissue sclerosis and microcirculatory changes. Localized scleroderma is considered a limited disease.

The patient presented with a localized sclerotic skin and claimed to be traumatic.

The studies of the laboratories did not produce interesting data.

A skin biopsy specimen from the buttock revealed a normal epidermis with dermal and hypodermal collagen sclerosis
\end{abstract}

The histological and clinical set of symptoms coincided with localized morphea.

Keywords: localized Scleroderma, morphea, trauma.

\section{INTRODUCTION}

Morphea is an uncommon skin disorder, featured by well demarcated round sclerotic taught skin. It usually present in a middle aged women. The etiology is unknown, however some state trauma as a triggering factor (Ahn et al 1995).

\section{CASE Report}

A 28-year primi-gravida Libyan lady in her last trimester visited the Dermatology OPD clinic, presented with a localized single elliptical slightly pale, whitish to pinkish taut hard area on her left mid quadrant buttock and said it is a bit painful. She gave a history of direct fall down on an object she do not recall precisely in Turkey since nine months when she was in her honey moon where she ignored it. At the present she is anxious about its look, pain and the changes that she noticed.

Her past medical history and family history were non-contributory.

On examination, she appeared healthy, and there an elliptical single grayish to pinkish, hard indurate area of about $5 \times 2 \mathrm{~cm}$ in the deep subcutaneous tissues at the outer aspect of the right buttock (figure1).

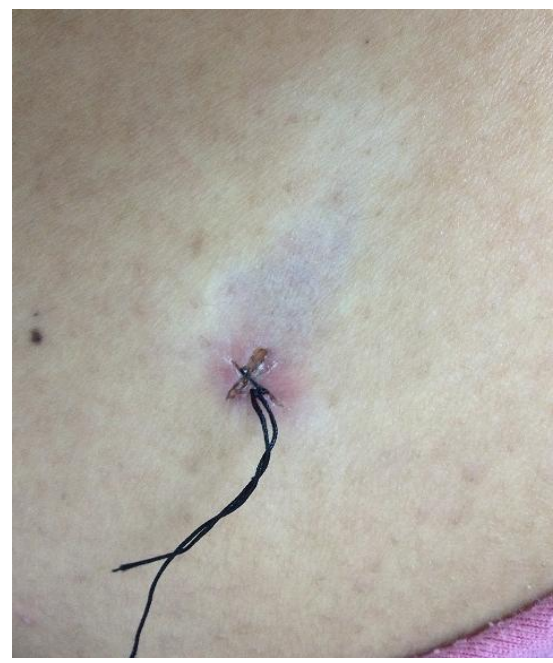

Figure1. Sclerotic white area 
Blood routine investigation was sent and all were within normal ranges. It was CBC, DLC and ESR.

Six mm punch biopsy shown changes linked with morphea and clinical diagnosis of localized scleroderma was confirmed by the histopathological reading by the pathologist (figure1).

The histology report revealed the findings of morphea: epidermis is unremarkable and the dermis is thick and composed of haphazardly arranged poorly collagen bundles with marked reduction of adipose tissue around the skin adenxia.

Many treatments has been described and employed in the literature such as phototherapy and intralesional steroids. The lady was pregnant, so I suggested the intralesional steroids as a trial to weight things out and she agreed with her husband.

Kenacort intralesional $40 \mathrm{mg} / \mathrm{ml}$ was given on the assumption to flatten and soften it out on weekly basis. She had received the first injection and then she dropped out and never came back (figure2).

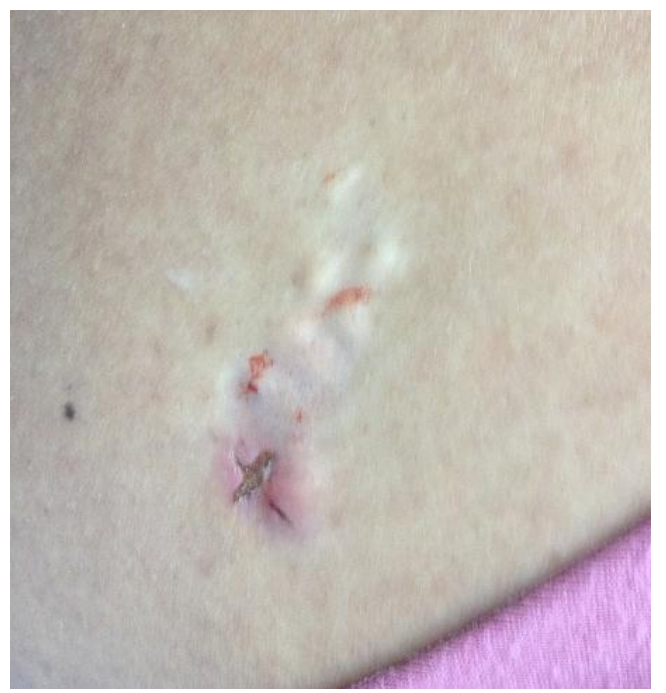

Figure2. Post IL kenacort

\section{DISCUSSION}

The lesion developed exactly at the site where the trauma had been happened as the lady reported.

Trauma has been implicated as an important trigger of morphea, both in children and in adults (Torrelo et al 2006, Wolf et al 2015). The local traumatization of the affected cutaneous area appears to be the triggering factor for the development of a sclerotic area in the lady buttock. Morphea usually occur without any specific provocations. However some initiators were claimed to be the culprit such as vaccination (Torrelo et al 2006), infections, injury (Ahn et al 1995), irradiation (Colver et al \& Verbov 1989, Laetsch et al 2011) and trauma (Touloei et al 2015).

Further claims in the literature documented as well such as burns, chickenpox, limb immobilization, spinal cord injury, vibration, arterial ischemia (Touloei et al 2015), exposure to chemicals, like organic solvents, toxic oil, l-tryptophan, silica, and silicone, has been related to scleroderma (Touloei et al 2015). Injection of a variety of chemical substances or drugs, such as paraffin, bleomycin, methysergide, pentazocine, vitamin $\mathrm{K} 1$, and corticosteroids, has been reported as a cause of scleroderma or scleroderma-like illness (Touloei et al 2015). Lastly, body piercing has been invoked as a cause of diffuse scleroderma in teenagers (Touloei et al 2015).

It is thought that three main components to trigger the morphea development, explicitly blood vessels, immune system and fibroblasts. The derangement of the first two would incur dysregulation of fibroblast as postulated. Even some genetic element has been found and where trauma could initiate the sclerosis process (Haustein 2001). Morphea usually takes some time to develop and the patient might forget to recall the initial incident. My patient seemed to recall the event of her problem sharply and her morphea was only localized to the site of trauma and did not affect any other parts of her body.

The mechanism of developing excessive collagen production at the blamed site is difficult to understand. It could be a release of certain mediators like cytokines, fibroblast, neuropeptides 
(Touloei et al 2015) and growth factor which could play a major role in the development of the sclerosis due to healing of the wound which induced fibroblast and thus more collagen production (Haustein 2001).

Many treatments has been explained and employed in the literature such as phototherapy and intralesional steroids (Buense et al 2012).

The troublesome skin disease of morphea can happen months to years after the incident, and is usually accompanied with considerable morbidity and ache, and in addition the worrisome cosmetic aspects. Consequently, it is critical to be attentive of such condition, and to endeavor to spot patients who might be at an increased risk of developing morphea. This can inform about future consideration in such cases.

'The author Dr EE declares that they have no competing interests, nor financial competing interests'

"Written informed consent was obtained from the patient for publication of this case report and any accompanying images.

\section{REFERENCES}

Colver GB, Rodger A, Mortimer PS, Savin JA, Neill SM, Hunter JA. Post-irradiation morphoea. Br J Dermatol. 1989; 120(6):831-5.

Verbov J. Post-irradiation morphoea. Br J Dermatol. 1989; 121(6):819-20.

Laetsch B, Hofer T, Lombriser N, Lautenschlager S. Irradiation-induced morphea: x-rays as triggers of autoimmunity. Dermatology. 2011; 223(1):9-12

Ahn JG, Kim YT, Lee CW. Trauma-induced isomorphic lesions in morphea--a brief case report. J Korean Med Sci. 1995; 10(2):152-4.

Wolf R, Wolf D, Ruocco V, Ruocco E. The role of skin trauma (isotopic and isomorphic) in the distribution of morphea. J Am Acad Dermatol. 2015; 72(3):560-1.

Buense R, Duarte IA, Bouer M. Localized scleroderma: assessment of the therapeutic response to phototherapy. An Bras Dermatol. 2012; 87(1):63-9.

Haustein UF.Systemic sclerosis following physical trauma.Acta Dermato-Venereologica [Acta Derm Venereol], 2001; Vol. 81 (1), pp. 63.

Touloei K, Wiener A, Glick BP. Solitary morphea profunda following trauma sustained in an automobile accident. Cutis. 2015;95(1):32-6.

Torrelo A; Suárez J; Colmenero I; Azorín D; Perera A; Zambrano A, Deep Morphea after Vaccination in Two Young Children. Pediatric Dermatology. 2006; Vol. 23 (5), pp. 484-7. 